\title{
A Rare Case of Bilateral Congenital Radial Head Dislocation: A Case Report
}

\author{
Dhurvas Ramlal Ramprasath ${ }^{1}$, Antony Jaya Micheal Esthak ${ }^{2}$
}

\begin{abstract}
Background: Congenital radial head dislocation by far is a rare condition and also the most common congenital anomaly of elbow. It causes symptoms such as joint stiffness, snapping, locking, or pain; however the diagnosis is sometimes made incidentally from X-rays. Surgical management includes osteotomy of radius, osteotomy of ulna, or radial head excision.

Aim and objective: The treatment goal is to ameliorate the symptoms and obtain a joint with a full range of motion.

Case description: Only unilateral cases have been described in literature until now. This article presents a case of bilateral congenital radial head dislocation in a pediatric girl with progressing valgus deformity, treated surgically by a newer technique. We successfully performed an ulnar osteotomy and distraction osteogenesis of ulna with an UMEX external fixator. Once the radial head was brought to the level of the joint, open reduction was done.

Conclusion: The clinical and functional outcomes were satisfactory.

Clinical significance: Even though various surgical options are available for the management of congenital radial head dislocation, radial head preserving surgery will benefit the patient on the long run by avoiding the development of distal radioulnar joint problems. Our procedure helps in achieving this goal.

Keywords: Bilateral, Congenital, Distraction osteogenesis, External fixator, Radial head dislocation, Ulna.

Journal of Orthopedics and Joint Surgery (2020): 10.5005/jp-journals-10079-1013
\end{abstract}

\section{BACKGROUND}

Congenital radial head dislocation is the most common congenital anomaly of the elbow. ${ }^{1}$ It usually occurs in association with other conditions ( $60 \%$ of the time) like scoliosis, mental retardation, nailpatella syndrome, and Klippel-Feil syndrome. ${ }^{2,3}$ The condition is usually bilateral. ${ }^{3,4}$ Majority of radial head dislocations are posterior (65\% of the cases), followed by anterior (15\%) and lateral (15\%). ${ }^{5}$ We are presenting a case of bilateral congenital radial head dislocation managed with distraction osteogenesis of ulna followed by open reduction of radial head.

\section{Case Description}

An 11-year-old female child born of non-consanguineous marriage presented at our outpatient department with short stature and deformity of both upper limbs since birth, with no difficulty in extension and flexion of both elbow joints. There was no history of trauma. Besides the increasing deformity, the patient had no complaints of pain or limitations. She had full flexion at her elbow and supination of her forearm. The deformity was creating cosmetic concerns (Fig. 1).

The anteroposterior and lateral radiographs of left elbow joint showed posterior dislocation of radial head with a lateral bowing of radius and ulna (Fig. 2). We decided to reduce the radial head indirectly by lengthening the ulna by distraction osteogenesis using an UMEX fixator.

Initially, we started with an external fixation of the proximal one third of the left ulna using an UMEX fixator with two proximal and two distal $2.5 \mathrm{~mm}$ Schanz pins. An osteotomy of ulna was performed at the middle of the proximal and distal pins. The distal radioulnar joint was transfixed with a mediolateral $2 \mathrm{~mm}$ K-wire. Distraction osteogenesis was initiated 1 week later. Distraction at
${ }^{1}$ Department of Orthopaedic Surgery, Chengalpattu Medical College Hospital, Chengalpattu, Tamil Nadu, India

${ }^{2}$ Department of Orthopaedic Surgery, Government District Headquarters Hospital, Kancheepuram, Tamil Nadu, India

Corresponding Author: Antony Jaya Micheal Esthak, Department of Orthopaedic Surgery, Government District Headquarters Hospital, Kancheepuram, Tamil Nadu, India, Phone: +91 9043055635, e-mail: michael.esthak@gmail.com

How to cite this article: Ramprasath DR, Esthak AJM. A Rare Case of Bilateral Congenital Radial Head Dislocation: A Case Report. J Orth Joint Surg 2020;2(2):66-69.

Source of support: Nil

Conflict of interest: None

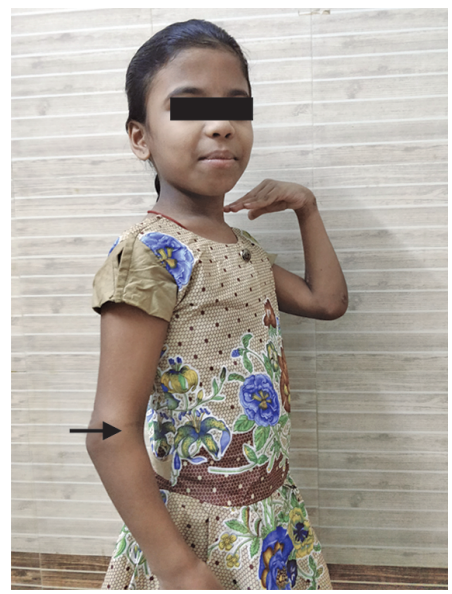

Fig. 1: Preoperative clinical picture showing abnormal radial head prominence

() The Author(s). 2020 Open Access This article is distributed under the terms of the Creative Commons Attribution 4.0 International License (https://creativecommons. org/licenses/by-nc/4.0/), which permits unrestricted use, distribution, and non-commercial reproduction in any medium, provided you give appropriate credit to the original author(s) and the source, provide a link to the Creative Commons license, and indicate if changes were made. The Creative Commons Public Domain Dedication waiver (http://creativecommons.org/publicdomain/zero/1.0/) applies to the data made available in this article, unless otherwise stated. 


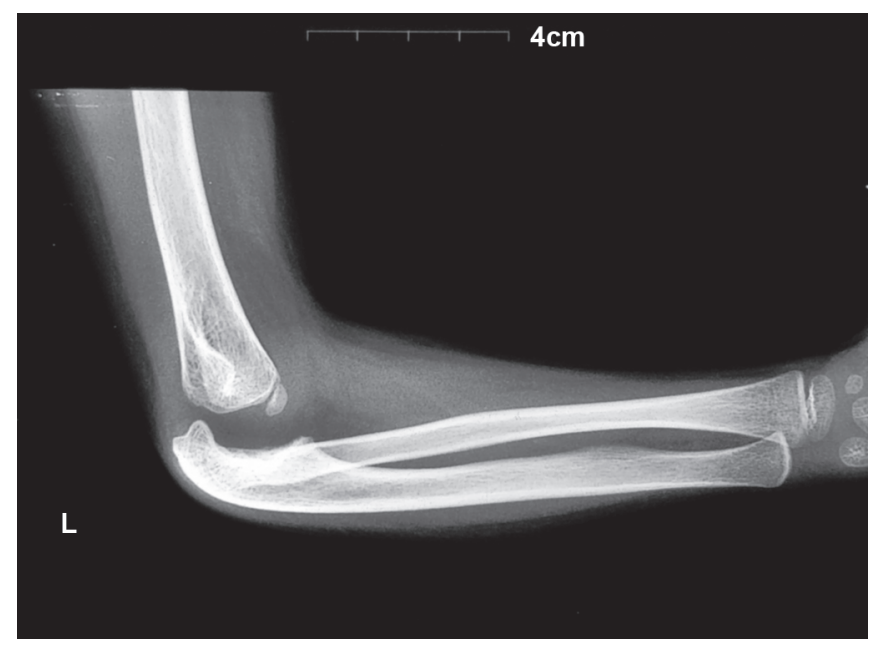

Fig. 2: Preoperative radiograph

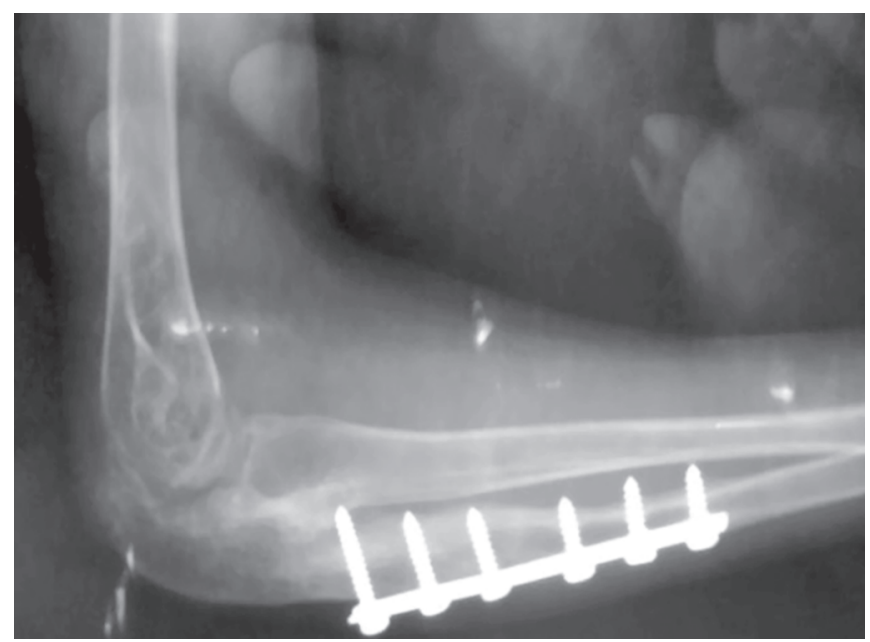

Fig. 4: Postoperative radiograph

the rate of $1 \mathrm{~mm}$ was done every alternate day, and the progress of distraction was monitored by weekly anteroposterior and lateral view radiographs for 4 weeks (Fig. 3).

After 4 weeks, the radial head was found to have descended below the lateral condyle of humerus. Hence, we planned open reduction and internal fixation of the radial head. Elbow joint was approached anteriorly and annular ligament was released. But radial head could not be reduced. Hence, we abandoned the procedure considering that furthermore distraction was necessary for reduction. Distraction was continued for another 2 weeks, and finally, we planned to reduce the radial head by open reduction and internal fixation through posterior approach.

After removing the UMEX fixator, the elbow joint was approached posteriorly, and radial head was identified, and capsulotomy was done to release it. But reduction was still difficult. So, we exposed the olecranon process which was found to be deformed due to the chronic dislocation of the radial head posteriorly. Intraoperatively, we found that the deformed olecranon was the cause of difficulty in reduction of the radial head. Hence, we performed an olecranon osteotomy, following which reduction was achieved. Stabilization was done with an ulno-humeral K-wire and a radiocapitellar K-wire. Postoperatively a plaster of paris slab support was given for 4 weeks.

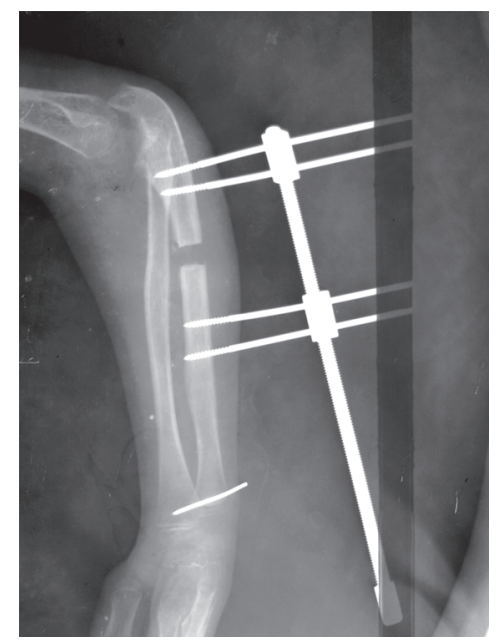

Fig. 3: Distraction osteogenesis

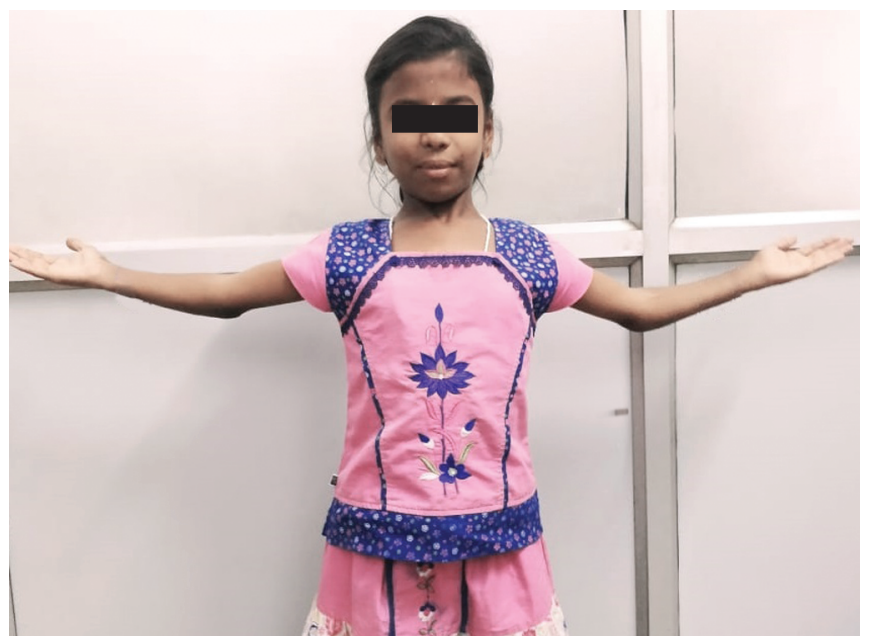

Fig. 5: Functional outcome

On the immediate postoperative radiographs, we found that the ulna was angulated laterally at the regenerate site. Correction of angulation was done by open reduction and internal fixation with a four-holed one-third tubular plate. Plaster cast was continued for 4 weeks.

Four weeks later, the K-wires were removed and elbow mobilization was started. Elbow mobilizing exercises were performed by the patient under supervision everyday (Fig. 4).

Next, the same procedure comprising distraction osteogenesis of ulna was performed on opposite side, followed by open reduction of radial head through posterior approach and application of transarticular K-wires and plaster of Paris. Mobilization was done after removal of K-wires at 6 weeks postoperatively. Finally, at 1-year follow-up, we achieved good functional outcome and cosmetic appearance (Fig. 5).

\section{Discussion}

Congenital radial head dislocations are often not noted until the age of 4 or 5 at which time some limitation of motion or deformity becomes evident. ${ }^{5}$ Surgery can be indicated because of pain, functional impairment, snapping, or cosmetic reasons. ${ }^{6}$ Surgical options include ulnar osteotomy, radial osteotomy, ${ }^{7}$ rotation 

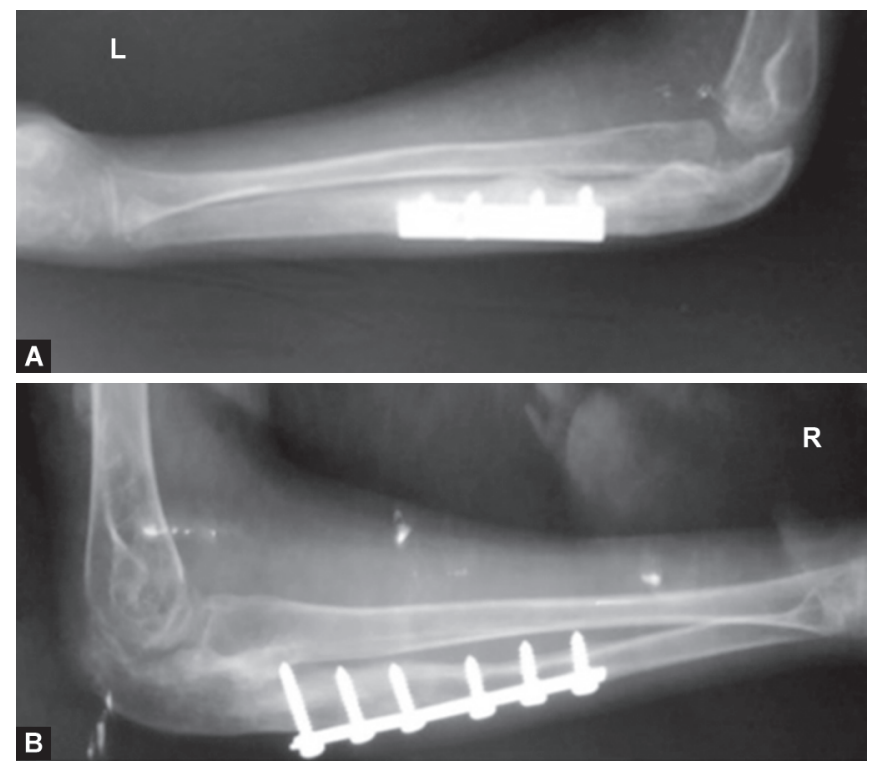

Figs $6 \mathrm{~A}$ and B: Postoperative follow-up radiograph after 1 year

osteotomy, ${ }^{4}$ reconstruction of annular ligament, ${ }^{8}$ and resection of radial head. Resection is advised in a symptomatic patient after reaching skeletal maturity. If resection is done earlier, complications include pain in the distal radioulnar joint due to proximalization of radius, instability, valgus deformation, weakness, and regrowth of proximal radius. $^{9-13}$

The dislocation of radial head and its associated features are now believed to be triggered by failure of development of a normal capitellum, which deprives the developing radial head of the contact pressure required for normal development and results in malformation of radiocapitellar joint. ${ }^{14}$

The asymptomatic children once they reach adolescence become symptomatic because of altered joint kinematics leading to pain, loss of motion, deformities, and osteochondral loose bodies. ${ }^{15}$ If the radial head can be reduced early, the deformity of the capitellum and the forearm may not occur or remodel with growth.

Karuppal et al. ${ }^{7}$ have done a two incision approach with osteotomy involving radial shaft. Through the first incision on the anterior aspect, the radial shaft was osteotomized. Through a second incision on the lateral border of elbow, open reduction of radial head was done. The overlapping part of radial shaft was trimmed. The reduction was stabilized with transarticular K-wire. This procedure is similar to the procedure of femoral shortening in the treatment of dysplastic dislocated hip joint.

In our case, we have performed an ulnar osteotomy followed by distraction. A radioulnar K-wire in the distal radioulnar joint guided the distal pull of radius along with ulna. Once the radial head approached the level of capitellum, through posterior approach open reduction of the radial head was done (Fig. 6). In this operative technique, we essentially avoided shortening of the radius.

In a study of 77 patients by Mardam-Bey et al. in 1979, 70 patients who were managed conservatively either developed pain and functional limitation or had significant cosmetic radial head prominence. $^{9}$

After 1980s, surgical management has been given priority in most of the literatures. ${ }^{12,13,16,17}$ The technique of surgical management can be decided by the bone which is more bowed. In our case, the ulna was more bowed; hence, we performed an ulnar osteotomy and achieved good reduction of the radial head.

\section{Conclusion}

Although there are several treatment options, it is difficult to identify the best method because of limited number of reported cases. In this case, we successfully reduced the radial head dislocation indirectly by ulnar osteotomy and distraction osteogenesis using an UMEX external fixator. To our knowledge, as per literature no cases have been treated by this method. This is a safer technique to treat congenital radial head dislocation. The functional outcome and cosmetic appearance was good.

\section{Clinical Significance}

Even though various surgical options are available for the management of congenital radial head dislocation, radial head preserving surgery will benefit the patient on the long run by avoiding the development of distal radioulnar joint problems. Our procedure helps in achieving this goal.

\section{References}

1. Sachar K, Mih AD. Congenital radial head dislocations. Hand Clin 1998;14(1):39-47.

2. Joseph PI, Richard P. The Netter Collection of Medical Illustrations: Musculoskeletal System. Part I - Upper Limb: Elsevier Health Sciences, Medical; 2012. p. 104.

3. Agnew DK, Davis RJ. Congenital unilateral dislocation of the radial head. J Pediatr Orthop 1993;13(4):526-528. DOI: 10.1097/01241398$199307000-00020$.

4. Echtler B, Burckhardt A. Isolated congenital dislocation of the radial head. Good function in 4 untreated patients after 14-45 years. Acta Orthop Scand 1997;68(6):598-600.DOI: 10.3109/17453679708999034.

5. Hughes $T$, Chung $C B$. Bone and cartilage injury. In: Chung $C B$, Steinbach LS. MRI of the Upper Extremity: Shoulder, Elbow, Wrist, and Hand, ch 12. Lippincott Williams \& Wilkins, Philadelphia, USA 2010. pp.487-488.

6. Kaas $L$, Struijs PAA. Congenital radial head dislocation with a progressive cubitusvalgus: A case report. StratTraum Limb Recon 2012;7(1):39-44. DOI: 10.1007/s11751-011-0126-z.

7. Karuppal R, Marthya A, Raman RV, et al. Case report: Congenital dislocation of the radial head - a two-in-one approach. F1000Res 2014;3:22. DOI: 10.12688/f1000research.3-22.v1.

8. Yamazaki $\mathrm{H}$, Kato $\mathrm{H}$. Open reduction of the radial head with ulnar osteotomy and annular ligament reconstruction for bilateral congenital radial head dislocation: A case with long-term follow-up. J Hand Surg Eur Vol 2007;32(1):93-97. DOI: 10.1016/j.jhsb.2006. 09.003.

9. Mardam-Bey T, Ger E. Congenital radial head dislocation. J Hand Surg Am 1979;4(4):316-320. DOI: 10.1016/S0363-5023(79)80067-2.

10. Kelly DW. Congenital dislocation of the radial head:spectrum and natural history. J Pediatr Orthop 1981;1(3):295-298. DOI: 10.1097/01241398-198111000-00009.

11. Miura T. Congenital dislocation of the radial head. J Hand Surg $\mathrm{Br}$ 1990;15(4):477-481. DOI: 10.1016/0266-7681(90)90095-L.

12. Bell SN, Morrey BF, Bianco AJ. Chronic posterior subluxation and dislocation of the radial head. J Bone Joint Surg Am 1991;73(3):392396. DOI: 10.2106/00004623-199173030-00010.

13. Campbell CC, Waters PM, Emans JB. Excision of the radial head for congenital dislocation. J Bone Joint Surg Am 1992;74(5):726-733. DOI: 10.2106/00004623-199274050-00011. 
14. Maresh MA. Linear growth of long bones of extremities from infancy through adolescence; continuing studies. AMA Am J Dis Child 1955;89(6):725-742. DOI: 10.1001/archpedi.1955.020501 10865010.

15. Wood WL, Robert BW, Raymond TM, et al. Weinstein. Lovell and Winter's Pediatric Orthopaedics. Lippincott Williams \& Wilkins, Medical; 2006(2):p.935.
16. Kim HT, Park BG, Suh JT, et al. Chronic radial head dislocation in children, part 2: Results of open treatment and factors affecting final outcome. J Pediatr Orthop 2002;22(5):591-597. DOI: 10.1097/01241398200209000-00005.

17. Futami T, Tsukamoto Y, Fujita T. Rotation osteotomy for dislocation of the radial head. 6 cases followed for 7 (3-10) years. Acta Orthop Scand 1992;63(4):455-456. DOI: 10.3109/17453679209154767. 